\title{
Compostagem de misturas de capim-elefante e torta de mamona com diferentes relações $C: N$
}

\author{
Marco A. de A. Leal ${ }^{1}$, José G. M. Guerra' ${ }^{1}$, José A. A. Espindola ${ }^{1}$ \& Ednaldo da S. Araújo ${ }^{1}$
}

\section{RESUMO}

A viabilidade econômica da compostagem está relacionada à utilização de matérias-primas abundantes, de custo competitivo e com níveis reduzidos de contaminação química e biológica. Seguindo esses critérios identifica-se a biomassa de capim-elefante e a torta de mamona como materiais bastante promissores. Objetivou-se, neste trabalho, determinar as características dos produtos finais e os índices de eficiência do processo de compostagem em três formulações da mistura de capim-elefante (Pennisetum purpureum) e torta de mamona com diferentes relações $C: N$, além de um tratamento de referência com a mistura de capim-elefante e biomassa de Crotalaria juncea. A compostagem da mistura de capim-elefante com torta de mamona possibilitou a obtenção de material orgânico estabilizado com elevado teor de $\mathrm{N}$, sem a necessidade de utilização de qualquer inoculante ou aditivo. Os compostos se estabilizaram aproximadamente aos 60 dias após o início da compostagem e apresentaram reduções de cerca de $50 \%$ de sua massa e $65 \%$ de seu volume, após 90 dias de compostagem. Compostos com os menores valores iniciais de relação C: $\mathrm{N}$ apresentaram as maiores perdas proporcionais de $\mathrm{N}$ durante a compostagem.

Palavras-chave: adubo orgânico, substrato, composto orgânico

\section{Composting of elephant grass and castor bean cake mixed with different $\mathrm{C}: \mathrm{N}$ ratios}

\begin{abstract}
The economic viability of composting is related to the use of abundant raw materials, with competitive cost and low levels of chemical and biological contamination. Following these criteria, the biomass of elephant grass and castor cake are identified as very promising materials. The aim of this study was to determine the characteristics of end products and efficiency indices of the composting process in three formulations of the mixture of elephant grass (Pennisetum purpureum) and castor bean cake with different $\mathrm{C}: \mathrm{N}$ ratios, and a reference treatment with the mixture of elephant grass biomass and Crotalaria juncea. The composting of the mixture of elephant grass with castor bean cake allows to obtain stabilized organic material, with high $\mathrm{N}$ content, with no need to use any inoculant or additive. Composts stabilized at approximately 60 days after initiation of composting provided reductions of approximately $50 \%$ of its mass and $65 \%$ of its volume after 90 days of composting. Composts with smaller initial $\mathrm{C}: \mathrm{N}$ ratios presented greater proportional loss of nitrogen during composting.
\end{abstract}

Key words: organic manure, substrate, organic compost 


\section{INTRODUÇÃO}

A compostagem de resíduos, subprodutos e outros materiais orgânicos, é um processo que pode atender plenamente a crescente demanda por fertilizantes orgânicos. Segundo Fialho et al. (2010), a compostagem é um processo exotérmico aeróbico em que resíduos orgânicosde diferentes origens são transformados em materiais relativamente estáveis.

O processo de compostagem geralmente requer a mistura de materiais com elevadas relações $\mathrm{C}: \mathrm{N}$, como palhadas diversas e serragem, com materiais ricos em N, como estercos e tortas. Segundo Leal et al. (2007), a viabilidade econômica da obtenção de adubos orgânicos e substratos através da compostagem está intimamente relacionada à utilização de matérias-primas abundantes, de custo competitivo e com reduzidos níveis de contaminação química e biológica. De acordo com esses critérios se identificam a biomassa de capim-elefante e a torta de mamona como materiais de origem vegetal muito promissores para serem utilizados como matéria-prima na compostagem.

O capim-elefante (Pennisetum purpureum Schum.) é uma das espécies forrageiras tropicais mais importantes em função do seu elevado potencial de produção de matéria seca, aceitabilidade e qualidade. Usado tanto para corte como para pastejo, a espécie apresenta boa adaptação à maioria dos ecossistemas tropicais (Pereira et al., 2000). De acordo com Quesada (2001), o capim-elefante está entre as espécies de alta eficiência fotossintética (metabolismo C4), que resulta na grande capacidade de acumulação de matéria seca. Definese como torta de mamona o subproduto da extração do óleo das sementes da mamoneira (Ricinus comunis L.). Segundo Azevedo \& Lima (2001), trata-se de produto com elevado teor de proteínas produzido na proporção aproximada de 1,2 tonelada para cada tonelada de óleo extraída.

$\mathrm{O}$ dimensionamento do processo de compostagem deve ser realizado de forma que características do produto final, tais como $\mathrm{pH}$, teor de $\mathrm{N}$, teor de carbono orgânico (C-orgânico) e relação C:N, estejam dentro dos limites estabelecidos pela legislação brasileira para fertilizantes orgânicos, com base na IN 25 do Ministério da Agricultura, Brasil (2009). Índices de eficiência da compostagem, como redução de massa, redução de volume e perda de nutrientes que ocorrem ao longo do processo, devem ser determinados visando estabelecer os coeficientes técnicos necessários para que esta técnica seja realizada de forma metódica.

Objetivou-se, neste trabalho, caracterizar o processo de compostagem da mistura de capim-elefante e torta de mamona, com diferentes valores iniciais de relação $\mathrm{C}: \mathrm{N}$ determinandose características dos produtos finais e índices de eficiência do processo.

\section{Material e Métodos}

O experimento foi conduzido entre março e junho de 2007, no Sistema Integrado de Produção Agroecológia (SIPA),

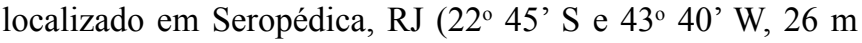
de altitude). Foram avaliados quatro tratamentos, sendo três proporções de mistura entre capim-elefante (Pennisetum purpureum) e torta de mamona, resultando em pilhas de materiais com três diferentes valores iniciais de relação C:N $(20$, 30 e 40) mais um tratamento constituído pela mistura de capimelefante e biomassa de crotalária (Crotalaria juncea) com valor inicial de relação $\mathrm{C}: \mathrm{N}$ igual a 30 . Não foram utilizados quaisquer tipos de inoculante ou aditivo. A relação $\mathrm{C}: \mathrm{N}$ e os teores de N, Ca, Mg, P e K das matérias-primas utilizadas estão apresentados na Tabela 1.

Tabela 1. Relação C: $\mathrm{N}$ e teores de N, Ca, Mg, P e K das matérias-primas utilizadas

\begin{tabular}{lrrrrrr}
\hline & Relação & $\mathbf{N}$ & $\mathbf{C a}$ & $\mathbf{M g}$ & $\mathbf{P}$ & $\mathbf{K}$ \\
\cline { 5 - 7 } & $\mathbf{C : N}$ & \multicolumn{5}{c}{$\mathbf{( g ~ k g - 1}^{-1} \mathbf{)}$} \\
Capim-elefante & 85,5 & 6,2 & 3,3 & 2,0 & 1,5 & 12,8 \\
Torta de mamona & 7,8 & 67,9 & 6,8 & 2,3 & 12,0 & 9,6 \\
Crotalária & 17,9 & 29,6 & 4,9 & 3,9 & 2,3 & 11,7 \\
\hline
\end{tabular}

Foram utilizados capim-elefante rebrotado com idade de quatro meses e crotalária com idade de três meses, ambos fragmentados em pedaços de $3,0 \mathrm{~cm}$ com auxílio de uma picadeira mecânica. Cada tratamento foi constituído por uma pilha de composto com 1,5 $\mathrm{m}$ de largura, $2,0 \mathrm{~m}$ de comprimento e 1,2 m de altura, instalada sobre lona plástica para evitar seu contato com o solo.

O período total de incubação foi de 90 dias. Amostragens foram realizadas semanalmente para avaliação da temperatura das pilhas. Aos 0, 7, 14, 21, 30, 45, 60 e 90 dias avaliaram-se $\mathrm{pH}$, teores de $\mathrm{N}$ e de C-orgânico e aos 0, 14, 30, 60 e 90 dias se avaliaram a variação da massa e do volume em relação à massa $\mathrm{e}$ volume iniciais, e variação do conteúdo de $\mathrm{N}$ quanto ao conteúdo inicial. Revolvimentos foram realizados aos 14, 30 e 60 dias.

As avaliações de temperatura e as amostragens para avaliação de $\mathrm{pH}$, teores de $\mathrm{N}$ e de C-orgânico foram realizadas com três repetições. Em cada repetição foram realizadas observações ou amostragens na metade da altura da pilha e em posições equidistantes das outras amostragens. A avaliação de temperatura foi realizada utilizando-se um termômetro de bulbo de mercúrio inserido a $50 \mathrm{~cm}$ de profundidade. As amostras dos compostos foram retiradas e imediatamente divididas em duas subamostras, em que uma foi acondicionada em saco plástico e armazenada em freezer para análise de $\mathrm{pH}$ enquanto a outra, para análise dos teores de $\mathrm{Ne}$ e de C-orgânico, foi acondicionada em saco de papel, secada em estufa $\left(>72 \mathrm{~h}, 65^{\circ} \mathrm{C}\right)$ e moída em moinho tipo Wiley.

A análise de $\mathrm{pH}$ foi realizada em solução de água destilada (5:1 $\mathrm{v} / \mathrm{v}$ ). As análises do teor de $\mathrm{N}$ foram realizadas no Laboratório da Embrapa Agrobiologia utilizando-se o procedimento operacional para análise de tecido foliar descrito por Silva (2009). O teor de C-orgânico foi determinado por perda de massa aquecida a 500 ${ }^{\circ} \mathrm{C}$ durante $2 \mathrm{~h}$, em forno do tipo mufla, através de amostras de $1000 \mathrm{mg}$ previamente secadas em estufa a $100^{\circ} \mathrm{C}$. Considerouse matéria orgânica o material perdido pela queima entre $100 \mathrm{e}$ $500^{\circ} \mathrm{C}$. O carbono orgânico foi calculado dividindo-se o teor de matéria orgânica pelo fator 1,72.

A variação da massa das pilhas de composto em relação à massa inicial foi calculada por meio dos valores da massa seca de cada pilha de composto após determinado período de tempo, comparado com o valor da massa seca da mesma pilha no início da compostagem. A massa seca de cada pilha de composto foi calculada em função da sua massa úmida e do teor de matéria seca determinado com base em três amostras/ 
repetições para cada pilha. A variação do volume em relação ao volume inicial foi calculada da mesma forma. A variação do conteúdo de $\mathrm{N}$ foi calculada considerando-se os valores de massa do composto e o teor deste nutriente nas diferentes épocas de amostragem.

A análise estatística foi realizada por meio de fatorial tempo de compostagem $\mathrm{x}$ tratamento, em delineamento inteiramente casualizado com três repetições, sendo apresentados os níveis de significância de cada fator e da interação entre os fatores. O comportamento de cada tratamento ao longo do processo de compostagem foi apresentado por meio de gráficos contendo os valores médios e o erro padrão.

\section{Resultados E Discussão}

A Tabela 2 apresenta o resumo dos resultados da análise de variância. Observa-se efeito significativo do tempo de compostagem em todas as características avaliadas indicando que todas elas sofreram variações significativas ao longo do processo de compostagem. Houve efeito significativo dos tratamentos sobre as características temperatura, $\mathrm{pH}$, teor de $\mathrm{N}$, teor de $\mathrm{C}$ e conteúdo de $\mathrm{N}$ em relação ao conteúdo inicial. Ocorreu interação entre o tempo de compostagem e tratamentos em quase todas as características estudadas demonstrando que os efeitos dos tratamentos variam em função do tempo de compostagem, sendo que a única exceção foi a característica proporção do conteúdo de $\mathrm{N}$ em relação ao conteúdo inicial.

Tabela 2. Resumo dos resultados da análise de variância do fatorial tempo de compostagem $x$ tratamentos, apresentando os níveis de significância de cada fator e da interação entre os fatores e o coeficiente de variação das características avaliadas

\begin{tabular}{|c|c|c|c|c|}
\hline & \multicolumn{3}{|c|}{ Nível de significância } & \multirow{2}{*}{ CV\% } \\
\hline & Tempo & Tratamento & Interação & \\
\hline Temperatura & $0,0000 * *$ & 0,0022 ** & $0,0000 * *$ & 4,62 \\
\hline $\mathrm{pH}$ & $0,0000 * *$ & $0,0000 * *$ & $0,0000 * \star$ & 1,24 \\
\hline Carbono & $0,0000 * \star$ & $0,3258 \mathrm{~ns}$ & 0,0352 * & 3,08 \\
\hline Nitrogênio & $0,0000 * \star$ & $0,0000 * \star$ & 0,0001 ** & 8,15 \\
\hline Relação C:N & $0,0000 * *$ & $0,0000 * *$ & 0,0256 * & 13,35 \\
\hline Proporção da massa inicial & $0,0000 * *$ & $0,3318 \mathrm{~ns}$ & 0,0200 * & 12,75 \\
\hline Proporção do volume inicial & $0,0000 * *$ & $0,0741 \mathrm{~ns}$ & $0,0008 * \star$ & 12,96 \\
\hline Proporção do N inicial & 0,0135 * & $0,0000 * *$ & $0,1802 \mathrm{~ns}$ & 12,54 \\
\hline
\end{tabular}

Valores das características avaliadas observados em cada tratamento ao final do processo de compostagem estão apresentados na Tabela 3.

Todos os tratamentos apresentaram temperaturas elevadas, acima de $60{ }^{\circ} \mathrm{C}$, logo no início do processo; em seguida, ocorreram reduções graduais até o momento em que foram realizados o segundo e o terceiro revolvimentos, quando ocorreram novas elevações da temperatura, conforme se observa na Figura 1. Este é um comportamento comumente observado em pilhas de compostagem e revela elevada atividade microbiana em todos os tratamentos estudados, independente do valor inicial da relação C:N. Comportamento semelhante também foi observado por autores como Heerden et al. (2002) e Jeong \& Kim (2001). Observa-se que, após aproximadamente 60 dias de incubação, as temperaturas das pilhas se aproximam da temperatura ambiente indicando a estabilização dos compostos. Segundo Gómez et al. (2006), a mensuração da elevação de temperatura na pilha de composto é um método prático para se estimar sua estabilização.

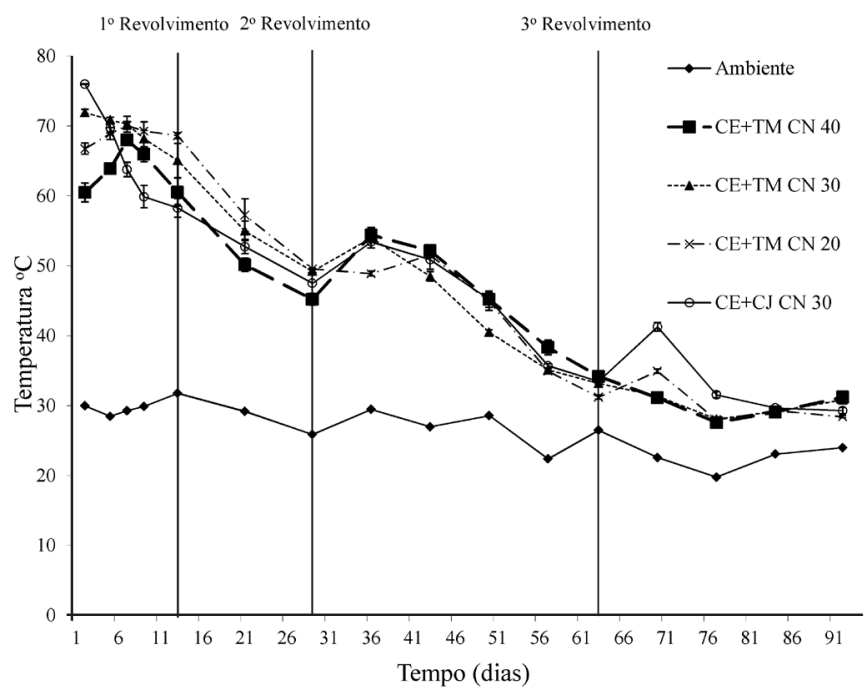

Obs.: CE+TM CN 40, CE+TM CN 30, CE+TM CN 20: capim-elefante + torta de mamona com valores iniciais de relação C:N iguais a 40, 30 e 20, respectivamente. $\mathrm{CE}+\mathrm{CJ}$ CN 30 capim-elefante + crotalária, com valor inicial de relação $\mathrm{C}: \mathrm{N}$ igual a 30

Figura 1. Temperaturas observadas durante o processo de compostagem de misturas de matérias-primas de origem vegetal com diferentes valores iniciais de relação C: $\mathrm{N}$ (média de três repetições \pm erro padrão). As linhas verticais no interior do gráfico indicam as datas em que ocorreram revolvimentos nos compostos

Tabela 3. Valores das características avaliadas observados ao final do processo de compostagem (90 dias). CE + TM CN 40, CE + TM CN 30, CE + TM CN 20: capim-elefante + torta de mamona, com valores iniciais de relação C: $N$ iguais a 40, 30 e 20, respectivamente. CE + CJ CN 30: capim-elefante + crotalária, com valor inicial de relação C:N igual a 30

\begin{tabular}{lcrrr}
\hline & CE+TM CN 40 & CE+TM CN 30 & CE+TM CN 20 & CE+CJ CN 30 \\
Temperatura $\left({ }^{\circ} \mathrm{C}\right)$ & $31,23 \mathrm{a}$ & $30,83 \mathrm{a}$ & $28,43 \mathrm{a}$ & $29,30 \mathrm{a}$ \\
pH & $7,40 \mathrm{a}$ & $7,32 \mathrm{a}$ & $6,67 \mathrm{~b}$ & $7,44 \mathrm{a}$ \\
Carbono $\left(\mathrm{mg} \mathrm{g}^{-1}\right)$ & $449,60 \mathrm{a}$ & $453,00 \mathrm{a}$ & $449,30 \mathrm{a}$ & $446,70 \mathrm{a}$ \\
Nitrogênio $\left(\mathrm{mg} \mathrm{g}^{-1}\right)$ & $21,70 \mathrm{C}$ & $24,20 \mathrm{c}$ & $26,80 \mathrm{~b}$ & $32,80 \mathrm{a}$ \\
Relação C:N & $20,87 \mathrm{a}$ & $18,72 \mathrm{a}$ & $16,88 \mathrm{a}$ & $13,64 \mathrm{~b}$ \\
Proporção da massa inicial (\%) & $47,29 \mathrm{a}$ & $45,88 \mathrm{a}$ & $49,79 \mathrm{a}$ & $37,40 \mathrm{a}$ \\
Proporção do volume inicial (\%) & $34,95 \mathrm{a}$ & $35,08 \mathrm{a}$ & $37,10 \mathrm{a}$ & $25,53 \mathrm{a}$ \\
Proporção do N inicial (\%)* & $77,43 \mathrm{a}$ & $62,84 \mathrm{~b}$ & $50,30 \mathrm{C}$ & $69,41 \mathrm{a}$ \\
\hline
\end{tabular}

* A interação entre tempo de compostagem e tratamentos não foi significativa

Médias seguidas da mesma letra não diferem entre si a nível de 0.05 pelo teste de Scott-Knott 
Os valores de $\mathrm{pH}$ (Figura 2A) se encontravam muito próximos da neutralidade, em todos os tratamentos, mantendose entre 6,5 e 7,5. Observa-se, com o aumento do tempo de incubação, que o tratamento com relação $\mathrm{C}: \mathrm{N}$ inicial igual a 20 foi o único que apresentou redução do $\mathrm{pH}$, que permaneceu inferior aos valores observados nos demais tratamentos, cuja ocorrência é devida, provavelmente, à acidificação induzida pela transformação de $\mathrm{N}$-amônio em $\mathrm{N}$-nitrato que ocorre durante a compostagem sendo que este processo foi mais intenso no tratamento com relação $\mathrm{C}: \mathrm{N}$ inicial igual a 20 , que apresentava os maiores teores de $\mathrm{N}$.

Os teores de C-orgânico foram semelhantes em todos os tratamentos (Figura 2B) com redução ao longo do período de compostagem e estabilização aos 60 dias de incubação, em aproximadamente $450 \mathrm{mg} \mathrm{g}^{-1}$. A semelhança no comportamento dos teores de C-orgânico em todos os tratamentos se deve, provavelmente, ao fato de todos eles utilizarem matérias-primas de origem inteiramente vegetal, sem qualquer mistura com materiais de origem mineral.

Os teores de $\mathrm{N}$ aumentaram ao longo do processo de compostagem atingindo, aos 60 dias, valores acima de 20

A.

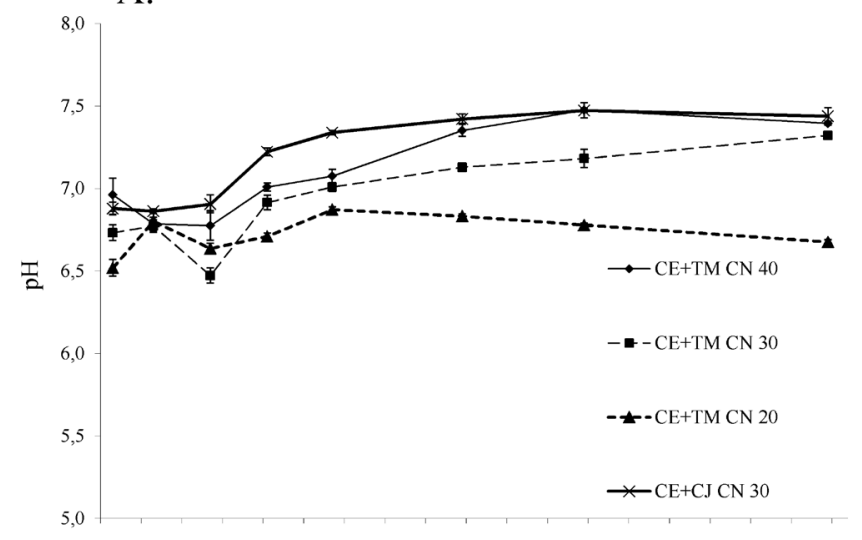

B.

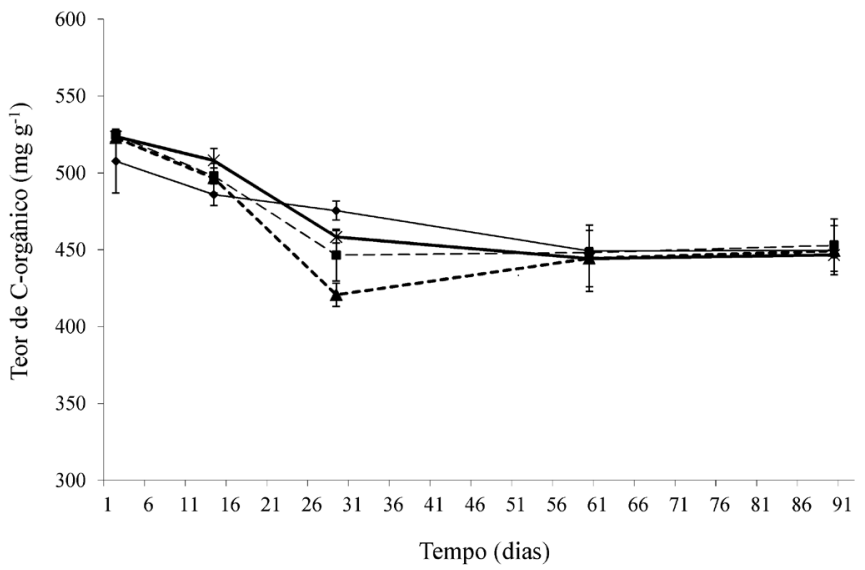

Obs.: CE+TM CN 40, CE + TM CN 30, CE + TM CN 20: capim-elefante + torta de mamona, com valores iniciais de relação C:N iguais a 40, 30 e 20, respectivamente. CE+CJ CN 30: capimelefante + crotalária, com valor inicial de relação $\mathrm{C}: \mathrm{N}$ igual a 30

Figura 2. Valores de pH (A) e teor de C-orgânico (B) durante o processo de compostagem de misturas de matérias-primas de origem vegetal com diferentes valores iniciais de relação C: $\mathrm{N}$ (média de três repetições \pm erro padrão)

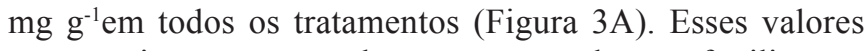
são superiores aos normalmente encontrados nos fertilizantes orgânicos tradicionais. Melo et al. (2008) observaram, ao caracterizar diversos resíduos orgânicos, teores de $\mathrm{N}$ total próximos a $11,0 \mathrm{mg} \mathrm{g}^{-1} \mathrm{em}$ esterco bovino. O tratamento obtido com a mistura de capim-elefante e crotalária apresentou o maior teor de $\mathrm{N}$ no final da compostagem em virtude, sem dúvida, da maior perda de massa por emissão de $\mathrm{CO}_{2}$ que ocorreu neste tratamento, o que resultou em maior concentração do $\mathrm{N}$ presente. Os teores de $\mathrm{N}$ observados nos tratamentos obtidos com base na mistura de capim-elefante e torta de mamona, não apresentaram grandes diferenças variando entre 21,7 a 26,8 $\mathrm{mg} \mathrm{g}^{-1}$ nos tratamentos com maior e com menor relação C:N inicial, respectivamente, apesar de o tratamento com relação $\mathrm{C}: \mathrm{N}$ inicial igual a 20 apresentar valor significativamente superior aos demais.

A relação C:N dos compostos diminuiu ao longo do processo de compostagem sendo que o tratamento com a mistura de capim-elefante e crotalária apresentou o menor valor (Figura 3B). Os tratamentos obtidos com base na mistura de capimelefante e torta de mamona apresentaram valores entre 20 e 17 nos tratamentos com maior e com menor relação C:N inicial, respectivamente. Todos os tratamentos apresentaram
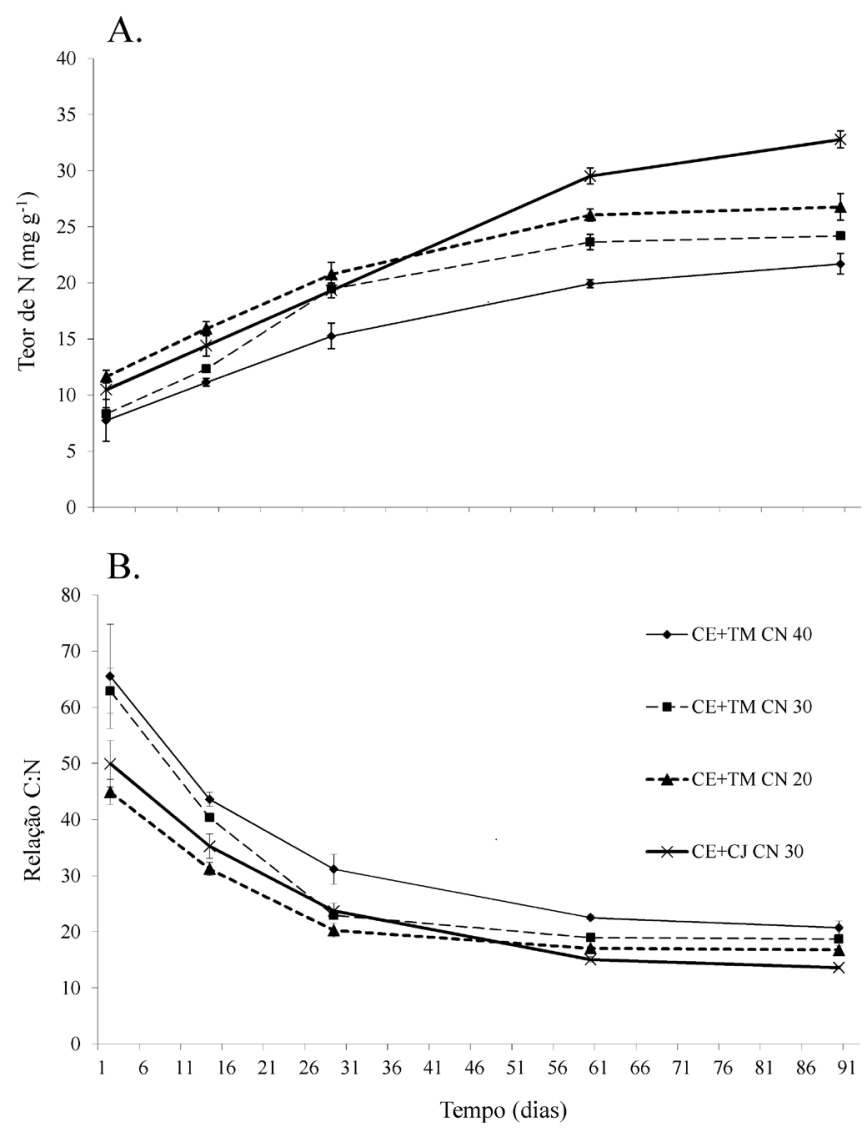

Obs.: CE+TM CN 40, CE+TM CN 30, CE+TM CN 20: capim-elefante + torta de mamona com valores iniciais de relação $\mathrm{C}: \mathrm{N}$ iguais a 40, 30 e 20, respectivamente. $\mathrm{CE}+\mathrm{CJ}$ CN 30: capim-elefante + crotalária com valor inicial de relação C:N igual a 30

Figura 3. Teor de $N(A)$ e relação $C: N(B)$ durante o processo de compostagem de misturas de matériasprimas de origem vegetal com diferentes valores iniciais de relação C: $\mathrm{N}$ (média de três repetições \pm erro padrão) 
estabilidade dos valores desta relação após 60 dias de incubação, aproximadamente.

É importante destacar que os teores de $\mathrm{N}$ e os valores da relação $\mathrm{C}: \mathrm{N}$ observados no início da compostagem permaneceram muito distantes dos valores esperados, independente do tratamento, o que pode ser atribuído à avaliação subestimada dos teores de $\mathrm{N}$ total nas amostras obtidas no início do processo de compostagem como resultado, provavelmente, da ocorrência de perda de N por volatilização durante a secagem das amostras em estufa de ventilação forçada. Segundo Bernal et al. (2009) a maior parte do N perdido durante a compostagem de resíduos animais é devida à volatilização de amônia que ocorre no início do processo.

Os resultados das variações de massa e de volume em relação à massa e ao volume inicial ao longo do processo de compostagem, estão apresentados nas Figuras 4A e 4B. Após 90 dias de compostagem não foram observadas diferenças significativas entre os tratamentos. Foram observadas perdas de massa e de redução de volume da ordem de 50 e $65 \%$, respectivamente, nos tratamentos obtidos com a mistura de capim-elefante e torta de mamona. Segundo Inácio \& Miller
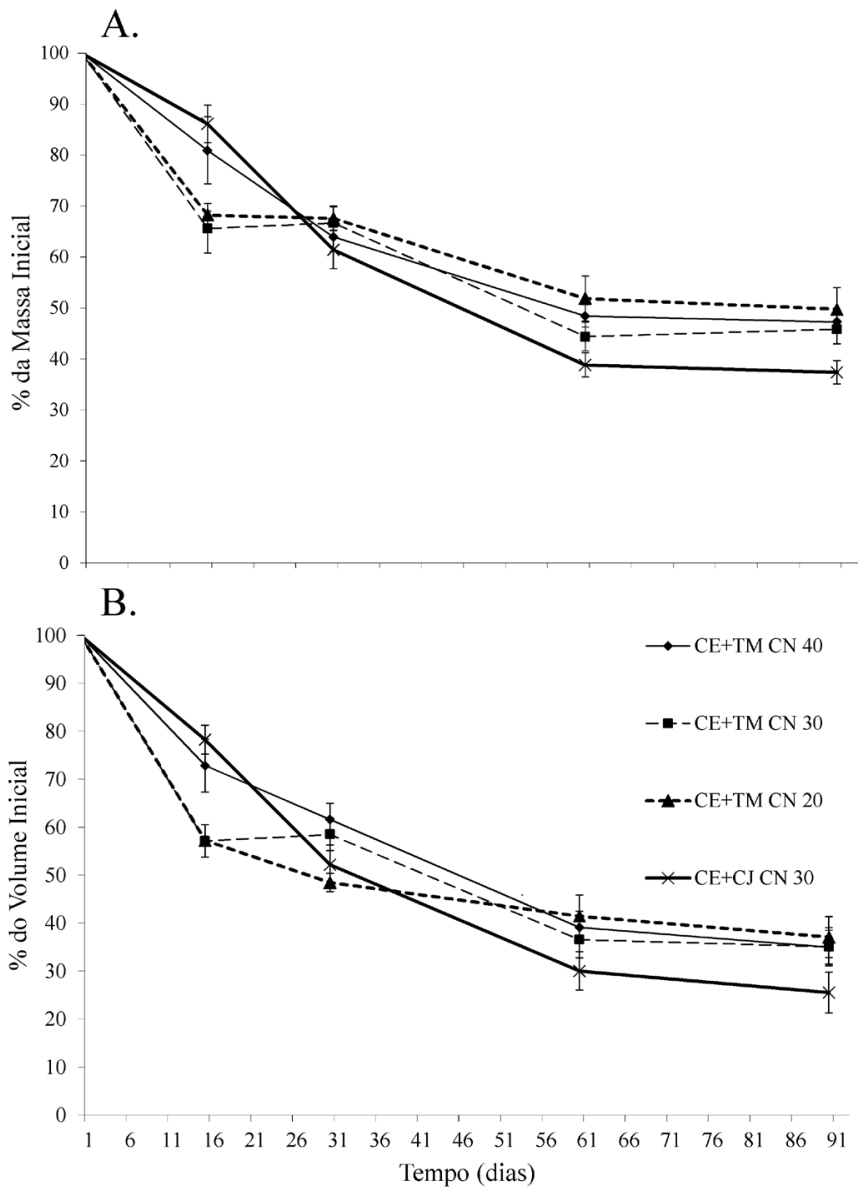

Obs.: CE+TM CN 40, CE+TM CN 30, CE+TM CN 20: capim-elefante + torta de mamona, com valores iniciais de relação $\mathrm{C}: \mathrm{N}$ iguais a 40,30 e 20, respectivamente. $\mathrm{CE}+\mathrm{CJ}$ CN 30 : capim-elefante + crotalária, com valor inicial de relação C:N igual a 30

Figura 4. Valores de massa seca (A) e volume (B) em porcentagem do valor inicial durante o processo de compostagem de misturas de matérias-primas de origem vegetal com diferentes valores iniciais de relação C:N (média de três repetições \pm erro padrão)
(2009) a perda de carbono através do $\mathrm{CO}_{2}$ e a intensa perda de vapor, são responsáveis por reduções de $25-50 \%$ no volume e $40-80 \%$ do peso total do composto. Bernal et al. (1998) constataram, estudando o processo de obtenção de compostos oriundos de diferentes misturas, perdas de carbono em até 70\% após 30 dias e até $90 \%$ após 70 dias.

Os resultados da variação do conteúdo de $\mathrm{N}$ em relação ao conteúdo inicial estão apresentados na Figura 5. A perda proporcional de $\mathrm{N}$ que ocorreu após 90 dias de compostagem está relacionada à relação $\mathrm{C}: \mathrm{N}$ inicial. A menor perda, da ordem de $23 \%$, foi observada no tratamento com C:N igual a 40 . A maior perda, da ordem de $50 \%$, foi observada no tratamento com $\mathrm{C}: \mathrm{N}$ igual a 20 demonstrando que quanto mais estreita a relação $\mathrm{C}: \mathrm{N}$ maior é a perda proporcional de $\mathrm{N}$ durante a compostagem. Orrico Júnior et al. (2010) observaram, estudando a compostagem de resíduos da produção avícola, redução de $71,6 \%$ do conteúdo de $\mathrm{N}$ após 60 dias de incubação.

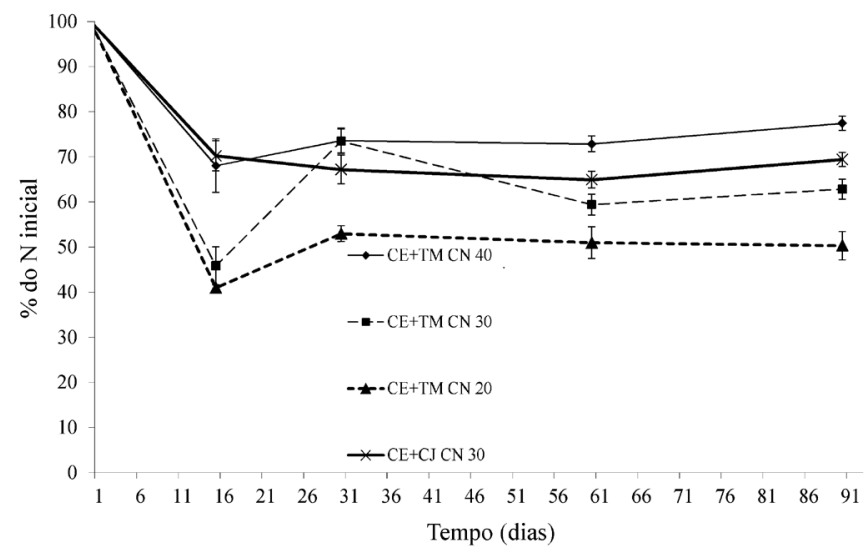

Obs.: CE + TM CN 40, CE + TM CN 30, CE + TM CN 20: capim-elefante + torta de mamona, com valores iniciais de relação C:N iguais a 40, 30 e 20, respectivamente. CE+CJ CN 30: capimelefante + crotalária, com valor inicial de relação C:N igual a 30

Figura 5. Valores de conteúdo de $\mathrm{N}$ em porcentagem do valor inicial, durante o processo de compostagem de misturas de matérias-primas de origem vegetal com diferentes valores iniciais de relação C:N (média de três repetições \pm erro padrão)

Destaca-se que após 90 dias de compostagem todos os tratamentos apresentaram valores de $\mathrm{pH}, \mathrm{N}$-total, C-orgânico e relação $\mathrm{C}: \mathrm{N}$ dentro dos limites estabelecidos pela IN 25 do Ministério da Agricultura.

$\mathrm{O}$ tratamento constituído pela mistura de capim-elefante e torta de mamona com relação $\mathrm{C}: \mathrm{N}$ inicial igual a 40, apresenta atividade microbiana e valores de perda proporcional de massa semelhantes ao tratamento com $\mathrm{C}: \mathrm{N}$ igual a 20 mas apresenta valores de perda proporcional de $\mathrm{N}$ inferior, o que demonstra maior eficiência na utilização do N. Esta formulação também requer menor proporção de torta de mamona para compor a mistura, o que representa menor custo de produção.

Segundo Schaub \& Leonard (1996) antes da compostagem o material deve ter a relação $C: N$ entre 25:1 e 35:1 e, se esta relação for muito baixa, o excesso de $\mathrm{N}$ será perdido como amônia; caso o conteúdo de $\mathrm{C}$ seja elevado, a compostagem será lenta e a maior parte do $\mathrm{C}$ será perdida como $\mathrm{CO}_{2}$. Neste trabalho não se observou redução da temperatura da pilha ou aumento na perda de massa no tratamento com relação $\mathrm{C}: \mathrm{N}$ inicial 
igual a 40 em razão, provavelmente, da utilização de torta de mamona como fonte de $\mathrm{N}$ visto que este material é rapidamente mineralizado disponibilizando seus nutrientes. Severino et al. (2005) demonstraram que a velocidade de mineralização da torta de mamona, medida pela respiração microbiana, é cerca de seis vezes mais rápida que a do esterco bovino e 14 vezes mais rápida que a velocidade de mineralização do bagaço de cana. A rápida mineralização do $\mathrm{N}$ contido na torta de mamona pode ter compensado a menor proporção deste nutriente no tratamento com relação C:N inicial igual a 40.

\section{CONClusÕes}

1. A compostagem da mistura de capim-elefante com torta de mamona possibilita a obtenção de material orgânico estabilizado, com elevado teor de N, sem a necessidade de utilização de qualquer inoculante ou aditivo.

2. Em compostos obtidos por meio da mistura de capimelefante e torta de mamona quanto mais estreita a relação $\mathrm{C}: \mathrm{N}$, maior é a perda proporcional de $\mathrm{N}$ durante a compostagem.

\section{Literatura Citada}

Azevedo, D. M. P.; Lima, E. F. (ed.). O Agronegócio da mamona no Brasil. Brasília: Embrapa Informação Tecnológica, 2001. 350p.

Bernal, M. P.; Alburquerque, J. A.; Moral, R. Composting of animal manures and chemical criteria for compost maturity assessment. A review. Bioresource Technology, v.100, p.5444-5453, 2009.

Bernal, M. P.; Sánchez-Monedero, M. A.; Paredes, C.; Roig, A. Carbon mineralization from organic wastes at different composting states during their incubation with soil. Agriculture Ecosystems \& Environment, v.69, p.175-189, 1998.

Brasil. Ministério da Agricultura Pecuária e Abastecimento. Secretaria de Defesa Agropecuária. Instrução Normativa n. 25, de 23 de Julho de 2009. Diário Oficial da República Federativa do Brasil. Poder Executivo, Brasília.

Fialho, L. L.; Silva, W. T. L.; Milori, D. M. B. P.; Simões, M. L.; Martin-Neto, L. Characterization of organic matter from composting of different residues by physicochemical and spectroscopic methods. Bioresource Technology, v.101, p.1927-1934, 2010.
Gómez, R. B.; Lima, F. V.; Ferrer, A. S. The use of respiration indices in the composting process: a review. Waste Management \& Research, v.24, p.37-47, 2006.

Heerden, I. van; Cronjé, C.; Swart, S. H.; Kotzé, J. M. Microbial, chemical and physical aspects of citrus wastes composting. Bioresource Technology, v.81, p.71-76, 2002.

Inácio, C. T.; Miller, P. R. M. Compostagem: Ciência e prática para gestão de resíduos orgânicos. Rio de Janeiro: Embrapa Solos, 2009. 156p.

Jeong, Y. K.; Kim, J. S. A new method for conservation of nitrogen in aerobic composting process. Bioresource Technology, v.79, p.129-133, 2001.

Leal, M. A. A.; Guerra, J. G. M.; Peixoto, R. T. G.; Almeida, D. L. Utilização de compostos orgânicos como substratos na produção de mudas de hortaliças. Horticultura Brasileira, v.25, p.392-395, 2007.

Melo, L. C. A.; Silva, C. A.; Dias, B. O. Caracterização da matriz orgânica de resíduos de origens diversificadas. Revista Brasileira de Ciência do Solo, v.32, p.101-110, 2008.

Orrico Júnior, M. A. P.; Orrico, A. C. A.; Lucas Júnior, J. Compostagem dos resíduos da produção avícola: Cama de frangos e carcaças de aves. Engenharia Agrícola, v.30, p.538-545, 2010.

Pereira, A. V.; Ferreira, R. P; Passos, L. P.; Freitas, V. P.; Verneque, R. S.; Barra, R. B.; Silva, C. H. P. e. Variação da qualidade de folhas em cultivares de capim-elefante (Pennisetum purpureum) e híbridos de capim-elefante $\mathrm{x}$ milheto ( $P$. purpureum $\mathrm{x} P$. glaucum), em função da idade da planta. Ciência e Agrotecnologia, v.24, p.490-499, 2000.

Quesada, D. M. Seleção de genótipos de capim-elefante (Pennisetum purpureum) a alta produção de biomassa e eficiência da fixação biológica de nitrogênio (FBN). Seropédica: UFRRJ, 2001. 140p. Dissertação Mestrado

Schaub, S. M.; Leonard, J. J. Composting: An alternative waste management option for food processing industries. Trends in Food Science \& Technology, v.7, p.263-268, 1996.

Severino, L.; Costa, F. X.; Beltrão, N. E. de M.; Lucena, A. M. A.; Guimarães, M. M. B. Mineralização da torta de mamona, esterco bovino e bagaço de cana estimada pela respiração microbiana. Revista de Biologia e Ciências da Terra, v.5, p.54-59, 2005.

Silva, F. C. (org.). Manual de análises químicas de solos, plantas e fertilizantes. 2.ed. Brasília: Embrapa Comunicação para Transferência de Tecnologia, 2009. 627p. 